\title{
Human Milk is the Feeding Strategy to Prevent Necrotizing Enterocolitis
}

\author{
Richard J. Schanler
}

Published online: 24 September 2014

(C) Springer Science + Business Media New York 2014

\begin{abstract}
The use of human milk in the neonatal intensive care unit clearly has short and long-term beneficial effects, but its role in the prevention of necrotizing enterocolitis (NEC) cannot be understated. Immaturity of the intestinal tract, barrier function, and mucosal defense contributes to NEC. Human milk feeding enhances maturity of the intestinal tract, barrier functions, and mucosal defenses by providing components such as immunoglobulin A, lactoferrin, lysozyme, oligosaccharides, epidermal growth factor, acetylhydrolase, erythropoietin, arginine and glutamine, and polyunsaturated fatty acids, and the ability to promote a commensal intestinal microflora.
\end{abstract}

Keywords Human milk - Donor human milk ·

Necrotizing enterocolitis

\section{Introduction}

The challenge to meet the nutritional goals of the extremely low birth weight (ELBW) infant while attempting to avoid serious complications and adverse outcomes such as necrotizing enterocolitis (NEC) can be overcome with human milk [1,2]. Such a diet meets nutritional needs as well as provides health benefits to the recipient. Why a

R. J. Schanler $(\bowtie)$

Division of Neonatal-Perinatal Medicine, Cohen Children's

Medical Center of New York, 269-01 76th Avenue,

New Hyde Park, NY 11040, USA

e-mail: schanler@nshs.edu

R. J. Schanler

Hofstra North Shore-LIJ School of Medicine, New Hyde Park, NY, USA human milk diet particularly benefits the health of the ELBW infant will be reviewed.

\section{Mother's Own Milk}

It has been demonstrated that a mother's own milk (MOM) diet is beneficial for ELBW infants because it is associated with prevention of late onset sepsis (LOS), NEC, and urinary tract infection [3-7]. That the host protection extends beyond the NICU stay is evidenced by fewer readmissions to the hospital for respiratory illness through almost 3 years [8]. It is estimated that there is a $5 \%$ decrease in the odds of being re-hospitalized for any infectious disease for every $10 \mathrm{~mL} / \mathrm{kg} /$ day human milk consumed in the NICU [8].

There is a $50 \%$ reduction in the rate of NEC and/or LOS and a shortened length of hospital stay among the ELBW infants receiving MOM at an average daily dose of more than $50 \mathrm{~mL} / \mathrm{kg}$ compared to $\mathrm{MOM}+$ formula, or formula alone [3]. That observation suggested that the dose of MOM (more than approximately $50 \mathrm{~mL} / \mathrm{kg} /$ day) was important to detect a beneficial health effect in ELBW infants [3].

The concept of a "dose-dependent" protective effect of human milk has been reported elsewhere. ELBW infants $(n=202)$ receiving more than $50 \% \mathrm{MOM}$ in the first 14 days after birth had an $83 \%$ reduction in the subsequent development of NEC compared to those receiving a diet of less than $50 \%$ MOM [9]. A daily intake of more than $50 \mathrm{~mL} / \mathrm{kg}$ for 4 weeks also is associated with a lower rate of neonatal sepsis [10]. The dose-dependent benefit should not be considered maximized at $50 \%$ intake. In a large retrospective analysis of 1,272 infants, the likelihood of NEC or death after 14 days was decreased by a factor of 
0.83 for each $10 \%$ increase in the proportion of total intake as human milk, suggesting the importance of dose and the predominance of a human milk diet [11].

Early initiation of human milk is advocated and practiced in the NICU. A Dutch study of 349 infants observed that the intakes of MOM $>50 \%$ during the first 5 days after birth was associated subsequently with a lower incidence of NEC, sepsis, and/or death during the first 60 days after birth [6]. An even stronger prediction model was observed if the intake of MOM was more than $50 \%$ during days 6-10 after birth [6]. These studies suggest that in the ELBW population the important early protective effects of a human milk diet are long-lasting.

There are effects of human milk on the gastrointestinal tract of ELBW infants that account for the better acceptance of this milk when compared to formula. There are significantly fewer gastric residuals and less time feedings were withheld in infants receiving MOM versus formula [3]. Milestones, such as achievement of full enteral feeding and length of hospital stay, are significantly shortened with the feeding of MOM. These milestones are achieved in nearly twice as many days when the percentile of human milk intake was less than $20 \%$ as compared to more than $80 \%$ [12].

Human milk feeding in ELBW infants also has been shown to protect against retinopathy of prematurity and, its most severe form, retinal detachment [13, 14]. These observations support a role of human milk as an antioxidant as well as containing factors that affect angiogenesis.

\section{Pathogenesis of NEC}

Clinical studies demonstrate that human milk protects the ELBW infant from NEC. To understand this relationship, it is important to describe a general overview of the pathogenesis of NEC. The etiology of NEC is unknown, but it is probably caused by multiple factors in a presumably genetically susceptible host. Factors implicated in its pathogenesis include prematurity (immature intestinal function), milk feeding (substrate), microbial colonization, impaired mucosal defense, and to some degree, circulatory instability. These factors act together to cause mucosal injury, which appears to be the initial event [15-17].

Bacterial colonization plays a pivotal role in the pathogenesis of NEC. Colonization of the normal GI tract occurs rapidly after delivery. The normal colonization is altered by the NICU environment. Immature intestinal motility predisposes to bacterial overgrowth which is unchecked due to the coexistence of an immature mucosal host defense. Increased gastrointestinal permeability potentiates bacterial translocation. Intestinal signaling becomes disrupted. Thus, these factors support and
Table 1 Factors in human milk reported to enhance protection from necrotizing enterocolitis

Oral IgA-IgG [28]

PAF acetylhydrolase [29]

Long-chain polyunsaturated fatty acids [30]

Erythropoietin [31]

Arginine and glutamine supplementation [32]

Epidermal growth factor [19]

Probiotics [33-35]

Lactoferrin [36]

Oligosaccharides [20•]

promote the invasion of pathogenic organisms into the circulation and set up an immune activation with an intense intestinal inflammatory response.

Contributing to the pathogenesis of NEC, milk feeding serves as a substrate for bacterial proliferation in the gut. Organic acids, short chain fatty acids, carbon dioxide, and hydrogen gas are produced by bacterial fermentation milk component nutrients. These products of fermentation may be toxic to intestinal epithelium and increase intestinal distention. In animal studies using an intestinal loop model, addition of casein creates a favorable milieu for infiltration of cellular elements and vasoactive compounds, leading to mucosal injury [18].

\section{Human Milk is Protective}

Preterm infants are susceptible to the development of NEC because immunologic and gastrointestinal immaturity result in altered host resistance. Mucosal defense in the intestinal tract is mediated by several interrelated components. Factors that contribute to innate resistance include luminal $\mathrm{pH}$, enzymes, mucins, epithelial barriers, and gut motility, as well as nonspecific antimicrobial factors such as lactoferrin and lysozyme. Factors present in human milk play a protective role by reducing inflammation and the subsequent invasion of pathogenic bacterial species in the gastrointestinal tract (Table 1). These factors include the enzyme platelet activating factor (PAF) acetylhydrolase, which blunts the immune activation sequence promoted by PAF. The local host defenses are enhanced by the addition of secretory $\operatorname{IgA}$, lactoferrin, lysozyme, and cytokines (IL10, IL-11) from human milk. Components in human milk, such as epidermal growth factor, nucleotides, and glutamine also stimulate intestinal maturity [19]. Human milk antioxidants, such as vitamin E, carotene, and glutathione, also reduce oxidative stress.

Immaturity of the gastrointestinal tract, including luminal function, motility, increased permeability, and barrier function, and diminished mucosal enzymes and GI 
trophic hormones, such as proteases and pepsin, and increased gastric $\mathrm{pH}$, also predispose the preterm infant to NEC [11].

Human milk oligosaccharides (HMO) are long-chain sugars, more than 150 such compounds that represent the third most prevalent constituent in human milk. HMOs are prebiotic agents that presumably act by enhancing proliferation of bifidobacteria and prevent of adhesion of pathogenic bacteria. In animal models studied under conditions that produce NEC, the HMOs are found to prevent intestinal injury compared to synthetic oligosaccharides. Indeed, human milk diets and formula diets that were supplemented with HMOs prevent intestinal injury while diets of formula with or without synthetic oligosaccharides fail to prevent intestinal injury in the model [20•]. The science of HMOs as luminal protective agents is intriguing.

Probiotics reduce NEC in neonates because they improve the intestinal barrier function, modulate the immune system, suppress the growth or epithelial binding and invasion, of pathogenic bacteria. It is likely that probiotics provide commensal bacterial colonization similar or additive to that promoted by human milk.

The Table 1 lists several components in human milk that in clinical and animal models employing individual components have been associated with protection from NEC.

\section{Donor Human Milk}

Mothers of ELBW infants may not be able to supply $100 \%$ of their infants' needs for MOM. One study of ELBW infants observed that only $30 \%$ of mothers were able to provide $100 \%$ of the milk for their ELBW infant [7]. Donor human milk (DM) has been considered an alternative to MOM and there has been an increase in the availability of DM in the recent years $[21,22]$. It has been shown that DM (vs formula) provides a protective effect against NEC and enhanced feeding tolerance in preterm infants [23]. However, DM has been associated with protein and mineral deficiencies and slower growth in preterm infants [23].

A randomized controlled trial to determine if DM is a suitable proxy to MOM was conducted in 210 infants, approximately 28 week gestation and with birth weights of approximately $1,000 \mathrm{~g}$ [7]. Infants were assigned to receive either DM or formula as supplements if their MOM volume was insufficient. The study found that the rates of sepsis and/ or NEC were similar in infants who received DM or preterm formula as supplements to MOM. The infants who continued to receive MOM had a $50 \%$ reduction in these outcomes. A possible explanation of these findings may relate to the bovine milk protein components of the human milk fortifiers used in the human milk groups. There is speculation that cow milk protein induces inflammation that is counteracted by the host defense properties of MOM, but these same properties are inadequately preserved after pasteurization [18, 24]. Thus, the infant fed bovine milk-based preparations with DM may be inadequately protected [7].

These observations prompted the investigation of an exclusive human milk diet (human milk-based human milk fortifier and DM if MOM was unavailable), appropriately fortified to meet the needs of the ELBW infant [25, 26]. A multicenter randomized trial in ELBW infants (mean birth weight $900 \mathrm{~g}$, gestational age 27 weeks) reported significantly lower rates of NEC and NEC requiring surgery in infants receiving the exclusive human milk diet than those receiving MOM with bovine-based human milk fortifiers and bovine-based formula if no MOM was available [25]. A further study in ELBW infants whose mothers were unable or unwilling to provide MOM identified similar benefits from an exclusive human milk diet than from formula [26]. That study also found markedly less need for parenteral nutrition in the group receiving an exclusive human milk diet. The investigation determined that six infants needed to be treated with an exclusive human milk diet to prevent one case of surgical NEC. To date, an exclusive human milk diet versus a diet containing bovine milk-based products has been studied in 260 ELBW infants [27••]. The summary data find that infants fed an exclusive human milk diet have lesser mortality (2\%), NEC (5\%), and NEC surgery (1\%) than those receiving a diet containing bovine milk-based products $(8,17$, and $12 \%$, respectively) [27••].

\section{Conclusion}

These data support recommendations of the American Academy of Pediatrics that encourage the use of MOM for all very low birth weight infants and DM if MOM is unavailable [2]. Although this recommendation is made to preclude the use of bovine milk-based formula in the preterm infant population, there remain no data that compare exclusive MOM versus exclusive DM. Given that newer human milk fortifiers not containing intact bovine protein are available, the possibility of such a future study can be considered. However, it is doubtful that an exclusive DM diet will be more beneficial than exclusive MOM.

Disclosure Richard J. Schanler declares that he has no conflict of interest.

Human and Animal Rights and Informed Consent This article does not contain any studies on animal subjects performed by the author. The clinical studies cited in this article that were performed by the author had the approval of the Institutional Review Board for Human Subjects Research at the appropriate institutions. 


\section{References}

Papers of particular interest, published recently, have been highlighted as:

- Of importance

•- Of major importance

1. Ahrabi AF, Schanler RJ. Human milk is the only milk for premies in the NICU! Early Hum Dev. 2013;89:S51-3.

2. Eidelman AI, Schanler RJ. Section on breastfeeding executive committee. Breastfeeding and the use of human milk: policy statement. Pediatrics. 2012;129:e827-41.

3. Schanler RJ, Shulman RJ, Lau C. Feeding strategies for premature infants: beneficial outcomes of feeding fortified human milk versus preterm formula. Pediatrics. 1999;103:1150-7.

4. Levy I, Comarsca J, Davidovits M, Klinger G, Sirota L, Linder N. Urinary tract infection in preterm infants: the protective role of breastfeeding. Pediatr Nephrol. 2009;24:527-31.

5. Lucas A, Cole TJ. Breast milk and neonatal necrotizing enterocolitis. Lancet. 1990;336:1519-23.

6. Corpeleijn WE, Kouwenhoven SM, Paap MC, van Vliet I, Scheerder I, Muizer Y, et al. Intake of own mother's milk during the first days of life is associated with decreased morbidity and mortality in very low birth weight infants during the first 60 days of life. Neonatology. 2012;102:276-81.

7. Schanler RJ, Lau C, Hurst NM, Smith EO. Randomized trial of donor human milk versus preterm formula as substitutes for mothers' own milk in the feeding of extremely premature infants. Pediatrics. 2005;116:400-6.

8. Vohr BR, Poindexter BB, Dusick AM, McKinley LT, Higgins RD, Langer JC, et al. Persistent beneficial effects of breast milk ingested in the neonatal intensive care unit on outcomes of extremely low birth weight infants at 30 months of age. Pediatrics. 2007;120:e953-9.

9. Sisk PM, Lovelady CA, Dillard RG, Gruber KJ, O'Shea TM. Early human milk feeding is associated with a lower risk of necrotizing enterocolitis in very low birth weight infants. J Perinatol. 2007;27:428-33.

10. Furman L, Taylor G, Minich N, Hack M. The effect of maternal milk on neonatal morbidity of very low-birth-weight infants. Arch Pediatr Adolesc Med. 2003;157:66-71.

11. Meinzen-Derr J, Poindexter B, Wrage L, Morrow AL, Stoll B, Donovan EF. Role of human milk in extremely low birth weight infants' risk of necrotizing enterocolitis or death. J Perinatol. 2009;29:57-62.

12. Ehrenkranz RA, Dusick AM, Vohr BR, Wright LL, Wrage LA, Poole WK. Growth in the neonatal intensive care unit influences neuro developmental and growth outcomes of extremely low birth weight infants. Pediatrics. 2006;117:1253-61.

13. Hylander MA, Strobino DM, Pezzullo JC, Dhanireddy R. Association of human milk feedings with a reduction in retinopathy of prematurity among very low birthweight infants. J Perinatol. 2001;21:356-62.

14. Okamoto T, Shirai M, Kokubo M, Takahashi S, Kajino M, Takase M, et al. Human milk reduces the risk of retinal detachment in extremely low-birthweight infants. Pediatr Int. 2007:49:894-7.

15. Kliegman RM, Walker WA, Yolken RH. Necrotizing enterocolitis: research agenda for a disease of unknown etiology and pathogenesis. Pediatr Res. 1993;34:701-8.

16. Holman RC, Stoll BJ, Clarke MJ, Glass RI. The epidemiology of necrotizing enterocolitis infant mortality in the United States. Am J Public Health. 1997;87:2026-31.
17. Neu J, Walker WA. Necrotizing enterocolitis. N Engl J Med. 2011;364:255-64.

18. Clark DA, Miller MJ. Intraluminal pathogenesis of necrotizing enterocolitis. J Pediatr. 1990;117:S64-7.

19. Dvorak B, Halpern MD, Holubec H, Williams CS, McWilliam DL, Dominguez JA, et al. Epidermal growth factor reduces the development of necrotizing enterocolitis in a neonatal rat model. Am J Physiol Gastrointest Liver Physiol. 2001;282:G156-64.

20. • Jantscher-Krenn E, Zherebtsov M, Nissan C, Goth K, Guner YS, Naidu $\mathrm{N}$ et al. The human milk oligosaccharide disialyllacto$\mathrm{N}$-tetraose prevents necrotising enterocolitis in neonatal rats. Gut. 2012;61:1417-25. Of importance because one of the first indications of the major role of oligosaccharides derived from human milk.

21. Delfosse NM, Ward L, Lagomarcino AJ, Auer C, Smith C, Meinzen-Derr $\mathrm{J}$, et al. Donor human milk largely replaces formula-feeding of preterm infants in two urban hospitals. J Perinatol. 2012;33:446-51.

22. Carroll K, Herrmann K. Introducing donor human milk to the NICU: lessons for Australia. Breastfeed Rev. 2012;20:19-26.

23. Boyd CA, Quigley MA, Brocklehurst P. Donor breast milk versus infant formula for preterm infants: a systematic review and metaanalysis. Arch Dis Child Fetal Neonatal Ed. 2007;92:F169-75.

24. Narayanan I, Prakash K, Murthy NS, Gujral VV. Randomised controlled trial of effect of raw and holder pasteurised human milk and of formula supplements on incidence of neonatal infection. Lancet. 1984;ii:1111-3.

25. Sullivan S, Schanler RJ, Kim JH, Patel AL, Trawöger R, KiechlKohlendorfer U, et al. An exclusively human milk-based diet is associated with a lower rate of necrotizing enterocolitis than a diet of human milk and bovine milk-based products. J Pediatr. 2010;156:562-7.

26. Cristofalo EA, Schanler RJ, Blanco CL, Sullivan S, Trawoeger R, Kiechl-Kohlendorfer $U$, et al. Randomized trial of exclusive human milk versus preterm formula diets in extremely premature infants. J Pediatr. 2013;163:1592-5.

27. •• Abrams SA, Schanler RJ, Lee ML, Rechtman DJ. Greater mortality and morbidity in extremely preterm infants fed a diet containing cow milk protein products. Breastfeed Med. 2014;9:281-85. This article summarizes the data from randomized trials by sullivan (26) and Cristofalo (27) indicating the benefits of an exclusive human milk diet.

28. Eibl MM, Wolf HM, Fürnkranz H, Rosenkranz A. Prevention of necrotizing enterocolitis in low-birth-weight infants by $\operatorname{IgA}-\mathrm{IgG}$ feeding. N Engl J Med. 1988;319:1-7.

29. Caplan MS, Lickerman M, Adler L, Dietsch GN, Yu A. The role of recombinant platelet-activating factor acetylhydrolase in a neonatal rat model of necrotizing enterocolitis. Pediatr Res. 1997;42:779-83.

30. Carlson SE, Montalto MB, Ponder DL, Werkman SH, Korones SB. Lower incidence of necrotizing enterocolitis in infants fed a preterm formula with egg phospholipids. Pediatr Res. 1998;44:491-8.

31. Juul SE, Ledbetter DJ, Joyce AE, Dame C, Christensen RD, Zhao $\mathrm{Y}$, et al. Erythropoietin acts as a trophic factor in neonatal rat intestine. Gut. 2001;49:182-9.

32. Bober-Olesinska K, Kornacka MK. Effects of glutamine supplemented parenteral nutrition on the incidence of necrotizing enterocolitis, nosocomial sepsis, and length of hospital stay in very low birth weight infants. Medycyna Wieku Rozwojowego. 2005;IX:325-53.

33. Hoyos AB. Reduced incidence of necrotizing enterocolitis associated with enteral administration of Lactobacillus acidophilus and Bifidobacterium infantis to neonates in an intensive care unit. Int J Infect Dis. 1999;3:197-202. 
34. Bin-Nun A, Bromiker R, Wilschanski M, Kaplan M, Rudensky B, Caplan M, et al. Oral probiotics prevent necrotizing enterocolitis in very low birth weight neonates. J Pediatr. 2005;147:192-6.

35. Lin H-C, Hsu C-H, Chen H-L, Chung M-Y, Hsu J-F, Lien R, et al. Oral probiotics prevent necrotizing enterocolitis in very low birth weigh preterm infants: a multicenter, randomized, controlled trial. Pediatrics. 2008;112:693-700.
36. Manzoni P, Rinaldi M, Cattani S, Pugni L, Romeo MG, Messner $\mathrm{H}$, et al. Bovine lactoferrin supplementation for prevention of late-onset sepsis in very low-birth-weight neonates: a randomized trial. JAMA. 2009;302:1421-8. 